\title{
Impact of food and fluid intake on technical and biological measurement error in body composition assessment methods in athletes
}

\author{
Ava $\operatorname{Kerr}^{1 *}$, Gary J. Slater ${ }^{1}$ and Nuala Byrne ${ }^{2}$ \\ ${ }^{1}$ School of Health and Sport Sciences, University of the Sunshine Coast, Sippy Downs, QLD 4556, Australia \\ ${ }^{2}$ School of Health Sciences, Faculty of Health, University of Tasmania, Launceston, TAS 7250, Australia \\ (Submitted 26 July 2016 - Final revision received 31 January 2017 - Accepted 17 February 2017)
}

\section{Abstract}

Two, three and four compartment (2C, 3C and 4C) models of body composition are popular methods to measure fat mass (FM) and fat-free mass (FFM) in athletes. However, the impact of food and fluid intake on measurement error has not been established. The purpose of this study was to evaluate standardised (overnight fasted, rested and hydrated) $v$. non-standardised (afternoon and non-fasted) presentation on technical and biological error on surface anthropometry (SA), 2C, 3C and 4C models. In thirty-two athletic males, measures of SA, dual-energy X-ray absorptiometry (DXA), bioelectrical impedance spectroscopy (BIS) and air displacement plethysmography (BOD POD) were taken to establish 2C, 3C and 4C models. Tests were conducted after an overnight fast (duplicate), about $7 \mathrm{~h}$ later after ad libitum food and fluid intake, and repeated $24 \mathrm{~h}$ later before and after ingestion of a specified meal. Magnitudes of changes in the mean and typical errors of measurement were determined. Mean change scores for non-standardised presentation and post meal tests for FM were substantially large in BIS, SA, 3C and 4C models. For FFM, mean change scores for non-standardised conditions produced large changes for BIS, 3C and 4C models, small for DXA, trivial for BOD POD and SA. Models that included a total body water (TBW) value from BIS (3C and 4C) were more sensitive to TBW changes in non-standardised conditions than 2C models. Biological error is minimised in all models with standardised presentation but DXA and BOD POD are acceptable if acute food and fluid intake remains below $500 \mathrm{~g}$.

Key words: Body composition assessment: Fat-free mass: Fat mass: Air displacement plethysmography: Dual-energy X-ray absorptiometry: Bioelectrical impedance spectroscopy: Surface anthropometry

Two compartment (2C) models of body composition assessment such as hydrodensitometry and air displacement plethysmography (BOD POD) separate the body into two chemically distinct compartments: fat mass (FM) and fat-free mass $(\mathrm{FFM})^{(1)}$. However, the application of a $2 \mathrm{C}$ model carries several assumptions including that the total body water (TBW) content of the FFM is $73.7 \%$ and that FM and FFM have densities of $0.9007 \mathrm{~g} / \mathrm{cm}^{3}$ and $1.1000 \mathrm{~g} / \mathrm{cm}^{3}$, respectively ${ }^{(2)}$. As a result, these methods may contain error due to the biological variability in these assumed constants ${ }^{(3,4)}$. This is most apparent for TBW which has the lowest density, yet is the largest component of $\mathrm{FFM}^{(2)}$ especially in athletic resistance trained males with high levels of $\mathrm{FFM}^{(5)}$. A three compartment (3C) model of body composition assessment, which combines measures of body density and TBW from ${ }^{2} \mathrm{H}$ dilution $\left(\mathrm{D}_{2} \mathrm{O}\right)$ rather than an assumed constant, affords greater validity and is shown to be closer to the reference method in body composition assessment ${ }^{(1,6)}$. The ability of bone health assessment technology such as dual-energy X-ray absorptiometry (DXA) to measure bone mineral content (BMC) allows the creation of a four compartment (4C) model where TBW and BMC are measured rather than assumed ${ }^{(6,7)}$.

Previous research has shown that bioelectrical impedance spectroscopy (BIS) and other 2C models such as DXA and BOD POD are highly influenced by subject presentation ${ }^{(8-11)}$. Factors such as acute food and fluid intake are known to impact on results ${ }^{(9,12-15)}$ as well as prior exercise and core body temperature ${ }^{(16)}$. As such, recommendations have been put forward advocating subjects present for assessment in a standardised manner, being fasted, rested and in a well-hydrated state $^{(9,10,17)}$. Unfortunately, this creates logistical issues with individuals only being able to be assessed early in the morning. Accounting for technical and biological error could afford an opportunity to measure individuals anytime throughout the day, or non-standardised presentation. However, the impact of acute food and fluid intake or physical activity in $2 \mathrm{C}, 3 \mathrm{C}$ and $4 \mathrm{C}$

Abbreviations: 2C, two compartment model; 3C, three compartment model; 4C, four compartment model; BIS, bioelectrical impedance spectroscopy; BOD POD, air displacement plethysmography; $\mathrm{D}_{2} \mathrm{O},{ }^{2} \mathrm{H}$ dilution; DXA, dual-energy X-ray absorptiometry; FFM, fat-free mass; FM, fat mass; SA, surface anthropometry; TBW, total body water.

* Corresponding author: A. Kerr, email akerr@usc.edu.au 
models of body composition assessment are still largely unknown.

The field-based method of surface anthropometry (SA) for body composition assessment includes measures of stature, body mass, skinfolds and girths; the combination of which provide valuable information regarding physique traits. To date the impact of standardised presentation on SA assessment has not been compared against different time points, or tested for reliability in individuals over the course of the day after ad libitum food, fluid ingestion and physical activity. Given the popularity of this technique, exploration of its reliability is warranted.

The aims of this study were: (1) to establish the technical error of $2 \mathrm{C}, 3 \mathrm{C}$ and $4 \mathrm{C}$ models as well as SA in body composition assessment in resistance trained male athletes, (2) to quantify typical errors of measurement for the methods, (3) to determine biological error in standardised $v$. nonstandardised presentation on multi-compartment model interpretation of body composition, and (4) to identify the biological impact introduced from ingestion of a specified meal.

\section{Methods}

\section{Subjects}

In all, thirty-two Caucasian individuals volunteered to participate in this study who met the inclusion criteria which included male, at least 2 years resistance training experience, with a minimum BMI of $\geq 25$. Subjects were excluded from the study if they were $>190 \mathrm{~cm}$ tall due to the limitation of the active scanning area of the DXA bed. The characteristics of all individuals are presented in Table 1. All subjects were informed of the nature and possible risks of the investigation before giving their written informed consent. This study was conducted according to the guidelines laid down in the Declaration of Helsinki and all procedures involving subjects were approved by the Human Research Ethics Committee of the University of the Sunshine Coast (Ethics Approval no. S/12/450).

\section{Experimental design}

Each subject underwent five identical testing sessions during a 27-h period (Fig. 1) with every measurement taken by the same technician. The sessions commenced with body mass measured in minimal clothing, a total body DXA scan immediately followed by a BIS estimation of TBW, a BOD POD test and assessment of subcutaneous FM via the skinfold technique, in that sequence. Each subject undertook tests $1\left(D_{1} T_{1}\right)$ and $2\left(\mathrm{D}_{1} \mathrm{~T}_{2}\right)$ on day 1 under standardised conditions (early morning, overnight fasted, euhydrated and well rested). $\mathrm{D}_{1} \mathrm{~T}_{2}$ was undertaken immediately after $\mathrm{D}_{1} \mathrm{~T}_{1}$ and test $3\left(\mathrm{D}_{1} \mathrm{~T}_{3}\right)$ was undertaken at a random time later in the afternoon, after ad libitum food, fluid and physical activity without intervention. The fourth test session on day $2\left(\mathrm{D}_{2} \mathrm{~T}_{4}\right)$ was also performed under standardised conditions. Subjects were then randomly assigned to a specified meal before being retested for the fifth time $\left(D_{2} T_{5}\right), 15$ min after meal ingestion. Comparison of these testing sessions allowed the calculation of typical error of
Table 1. Descriptive statistics for body composition variables (Mean values and standard deviations)

\begin{tabular}{|c|c|c|c|}
\hline \multirow[b]{2}{*}{ Variables } & \multicolumn{2}{|c|}{$n 32$} & \multirow[b]{2}{*}{ Range } \\
\hline & Mean & SD & \\
\hline Age (years) & 31 & 7 & $18-47$ \\
\hline Height (cm) & $182 \cdot 5$ & 7 & $168 \cdot 7-191.9$ \\
\hline BMI $\left(\mathrm{kg} / \mathrm{m}^{2}\right)$ & 27 & 3 & $25-33$ \\
\hline USG & 1.020 & 0.008 & $1.002-1.028$ \\
\hline Mass $(\mathrm{kg})$ & 91.5 & $10 \cdot 1$ & $75 \cdot 1-114 \cdot 5$ \\
\hline BMC (kg) & 3.84 & 0.42 & $2 \cdot 89-4.67$ \\
\hline TBW (kg) & $57 \cdot 26$ & $5 \cdot 77$ & $47 \cdot 11-71.06$ \\
\hline Skinfolds sum of $8(\mathrm{~mm})^{\star}$ & 82 & 30 & $36-172$ \\
\hline \multicolumn{4}{|l|}{ FM (kg) } \\
\hline BOD POD & $16 \cdot 8$ & $6 \cdot 4$ & $6 \cdot 4-32 \cdot 0$ \\
\hline BIS & $13 \cdot 3$ & $7 \cdot 2$ & $1 \cdot 1-31 \cdot 0$ \\
\hline DXA & $17 \cdot 1$ & $6 \cdot 9$ & $5 \cdot 0-33 \cdot 1$ \\
\hline $3 C$ & $15 \cdot 2$ & $6 \cdot 7$ & $3.7-31.9$ \\
\hline $4 \mathrm{C}$ & $15 \cdot 2$ & $6 \cdot 7$ & $3 \cdot 8-31 \cdot 7$ \\
\hline SA & $10 \cdot 8$ & 0.4 & $5 \cdot 2-22 \cdot 9$ \\
\hline \multicolumn{4}{|l|}{ FFM (kg) } \\
\hline BOD POD & $74 \cdot 8$ & 7.5 & $60 \cdot 7-90 \cdot 0$ \\
\hline BIS & $78 \cdot 2$ & 7.9 & $64 \cdot 4-97 \cdot 1$ \\
\hline DXA & 74.7 & $7 \cdot 6$ & $60 \cdot 0-91 \cdot 3$ \\
\hline $3 C$ & $76 \cdot 4$ & 7.5 & $62.5-93.6$ \\
\hline $4 \mathrm{C}$ & 76.4 & $7 \cdot 6$ & $62 \cdot 3-93 \cdot 5$ \\
\hline SA & $80 \cdot 7$ & 9.8 & $68 \cdot 3-102 \cdot 4$ \\
\hline
\end{tabular}

USG, urine specific gravity; BMC, bone mineral content; TBW, total body water; BOD $\mathrm{POD}$, air displacement plethysmography; BIS, bioelectrical impedance spectroscopy; DXA, dual-energy X-ray absorptiometry; 3C, three compartment model; 4C, four compartment model; SA, surface anthropometry; FM, fat mass; FFM, fatfree mass.

* Triceps, subscapular, biceps, illiac crest, supraspinale, abdominal, front Thigh, medial calf.

measurement (TEM), random within-day biological variability, between-day biological variability, and the impact of a predetermined quantity of food and fluid on body composition.

\section{Subject presentation}

Guidance was provided on both days to ensure subject presentation was standardised for three of the tests $\left(D_{1} T_{1}, D_{1} T_{2}\right.$ and $\mathrm{D}_{2} \mathrm{~T}_{4}$ ). Subjects were required to present overnight fasted and well rested (no prior physical activity) on the mornings before $\mathrm{D}_{1} \mathrm{~T}_{1}$ and $\mathrm{D}_{2} \mathrm{~T}_{4}$. They were asked to wear minimal fitted clothing with metal objects and jewellery removed, plus clothing checked for metal zips or studs. Hydration status was assessed by a mid-stream sample of urine provided by the subjects early on the mornings before testing $\left(\mathrm{D}_{1} \mathrm{~T}_{1}\right.$ and $\left.\mathrm{D}_{2} \mathrm{~T}_{4}\right)$. The specific gravity of the urine sample was measured using a digital refractometer (UG-Alpha; Atago Corporation). All subjects voided their bladder before tests.

\section{Dual-energy X-ray absorptiometry}

All DXA scans were undertaken in the whole body mode on a pencil beam DXA scanner (Lunar DPX; GE Healthcare) with analysis performed using GE enCORE version 13.60 software (GE Healthcare) with the combined Geelong/Lunar reference database. CV for the laboratory being $0 \cdot 1,2 \cdot 2,0 \cdot 6$ and $1 \cdot 0 \%$ for $\mathrm{BM}, \mathrm{FM}$, lean mass and BMC respectively. The DXA was calibrated with phantoms as per the manufacturer's guidelines each day 

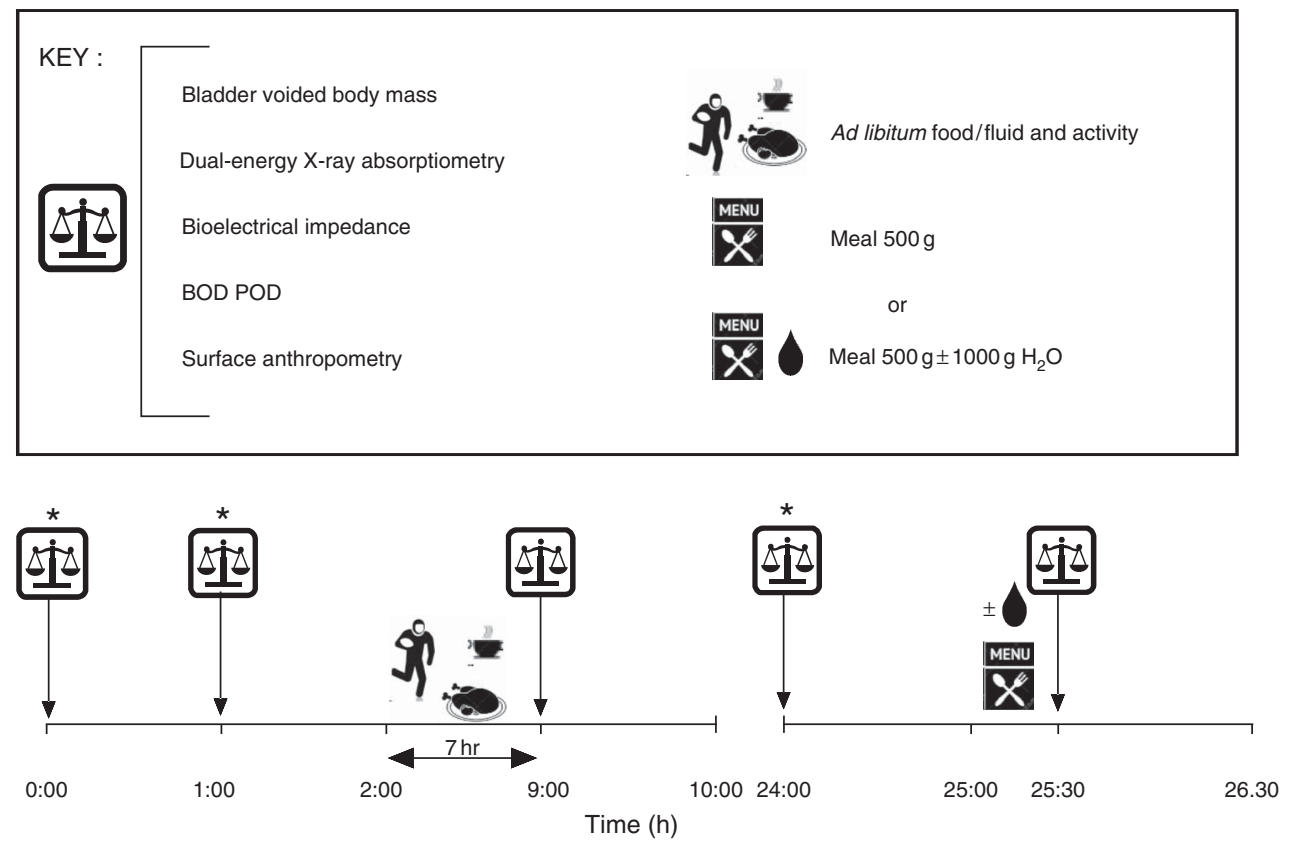

Fig. 1. Study design of five testing sessions conducted over $27 \mathrm{~h} . \mathrm{BOD} P O D, P O D$, air displacement plethysmography. ${ }^{*}$ Tests conducted in accordance with best practice guidelines.

before measurements were taken. All scans were conducted by the same Queensland Radiation Health licensed technician using the standard thickness mode as determined by the auto scan feature in the software and all safety protocols as per the Institution's Radiation Safety Protection Plan were adhered to.

The scans were performed according to a protocol developed that emphasises a consistent positioning of subjects on the DXA scanning bed ${ }^{(10)}$ as previously described ${ }^{(18)}$. In addition, two Velcro straps were used to minimise any subject movement during the scan as well as provide a consistent body position for subsequent scans. One strap was secured around the ankles above the foot positioning pad and the other strap was secured around the trunk at the level of the mid forearms ${ }^{(19)}$. All scans were analysed automatically by the DXA software but all regions of interest were reconfirmed before being included in the subsequent statistical analysis.

\section{Bioelectrical impedance spectroscopy}

Immediately after each DXA scan whilst the subjects were still positioned on the DXA scanning bed, TBW was measured using the BIS device, SFB7 (ImpediMed) device. Subject positioning was standardised to ensure they lay in the supine position on the non-conductive foam mattress without contact to the metal side supports of the DXA scanner for a minimum of $15 \mathrm{~min}$ before BIS measurements ${ }^{(20)}$. The BIS was calibrated as per the manufacturer's instructions with each participant's stature, body mass, age and sex programmed into the unit. Sites of attachment for the electrodes (ImpediMed) were first shaved and cleaned with alcohol wipes before the dual-tab electrodes were attached as follows: one electrode was attached centrally on the top side of the wrist in alignment with the ulnar head and $5 \mathrm{~cm}$ lower on the dorsal surface of the hand. The second electrode was attached centrally on the dorsal surface of the ankle between the lateral and medial malleoli and $5 \mathrm{~cm}$ lower on the dorsal surface of the foot which is in accordance with previous guidelines $^{(5)}$. The SFB7 measures impedance using 256 frequencies between 4 and $1024 \mathrm{kHz}$ to estimate TBW based on a Cole-Cole plot $^{(21)}$. Three measurements were taken consecutively and the median of these used in subsequent analysis. The BIS estimates of FM and FFM from complex algorithms created a field-based 2C model of physique assessment ${ }^{(22)}$.

\section{Air displacement plethysmography}

Immediately after TBW measurement, assessment of body density was undertaken using the BOD POD (Life Measurement Instruments) following the recommended procedures of the manufacturer ${ }^{(23)}$ utilising a predicted thoracic lung volume $\left(\mathrm{V}_{\mathrm{TG}}\right)$ estimation. Subjects wore Lycra clothing and a silicone swim cap, with all metal objects removed before measurement. Body density was calculated by the BOD POD's software system (COSMED version 5.3.2) as follows:

$$
D(\text { density })=\text { Mass }(\text { scale }) / \text { Volume }(\text { BOD POD }) \text {. }
$$

An estimate of FM and FFM was obtained after using the simple $2 \mathrm{C}$ model to calculate $\% B F$ as defined by the Siri equation $^{(3)}$, as follows:

$$
\% B F=(497 \cdot 1 / \text { body density })-451 \cdot 9 .
$$

\section{Surface anthropometry}

Immediately after completion of the BOD POD assessment, duplicate skinfold measurements were taken according the International Society of the Advancement of Kinanthropometry 
(ISAK) technique by the same technician certified by ISAK as previously described $^{(24)}$. The intra TEM of $0.2 \mathrm{~mm}$ and $0.6 \%$ for the technician was calculated by taking the difference between the first and second measurement $(d)$, squaring it $\left(d^{2}\right)$, adding them up for each subject $\left(d^{2}\right)$, dividing by $2 n$ (where $n$ is the number of subjects), and taking the square root. Therefore:

$$
T E M=\sqrt{ }\left[\sum d^{2} /(2 n)\right] .
$$

The sum of eight skinfolds was determined following measurements of the triceps, biceps, sub scapulae, iliac crest, supra-spinale, abdominal, quadriceps and calf skinfold using a calibrated skinfold caliper (Harpenden; Baty International). Due to the similar procedure, equipment and population used, the $4 \mathrm{C}$ validated Evans equation of three skinfolds (triceps, abdominal and thigh) was utilised to calculate $\% B F$ as follows ${ }^{(25)}$ :

$$
\begin{aligned}
\% B F= & 8.997+0.24658 \times(3 S K F)-6.343 \times(\text { gender }) \\
& -1.998 \times(\text { race }) .
\end{aligned}
$$

Stretch stature was measured with a stadiometer (Harpenden; Holtain Limited) to the nearest $0 \cdot 1 \mathrm{~cm}$. Body mass was measured on a calibrated scale to the nearest $0.01 \mathrm{~kg}$ (SECA GMBH).

\section{Three and four compartment models}

Utilising the body density values obtained by the BOD POD and the TBW estimations from the BIS, a $3 \mathrm{C}$ model was created for percent body fat calculated using the Siri equation as described by Withers et $a l .{ }^{(7)}$ :

$\% B F=211 \cdot 5 /$ body density $-78 \cdot 0 \times($ TBW $/$ body mass $)-134 \cdot 8$.

Similarly for the $4 \mathrm{C}$ model, the additional variable of BMC measured from DXA was incorporated to calculate percent body fat using the Withers et al. equation ${ }^{(7)}$ :

$$
\begin{aligned}
\% B F= & 251.3 / \text { body density }-73.9 \times(\text { TBW } / \text { body mass }) \\
& +94.7 \times(\text { bone mineral mass } / \text { body mass })-179.0
\end{aligned}
$$

Both equations were then converted to obtain estimates of FFM (kg) and FM (kg).

\section{Meal intake intervention}

After $\mathrm{D}_{2} \mathrm{~T}_{4}$ all subjects were provided with a standard $500 \mathrm{~g}$ breakfast meal consisting of wholemeal toast (four slices), butter, jam or Vegemite (Mondelez International) and a Musashi (Vitaco Health Australia) P30 $375 \mathrm{ml}$ protein drink with a nutrient profile typical of an average meal consumed by athletes ${ }^{(26)}$. The total volume of fluid and food was randomly assigned to the thirty-two subjects and scaled into two different portion sizes representing a $500 \mathrm{~g}$ meal (62 g carbohydrate, $36 \mathrm{~g}$ protein, $10 \mathrm{~g}$ fat, $340 \mathrm{ml}$ fluid) ( $n$ 16) or a $500 \mathrm{~g}$ meal plus 1 litre of water ( $n$ 16), respectively. $\mathrm{D}_{2} \mathrm{~T}_{5}$ was undertaken 15 (SD 3$)$ min after commencement of the meal for all subjects.

\section{Statistical analysis}

A customised spreadsheet (www.sportsci.org) was used to derive reliability statistics for comparing precision in the estimate of FFM and FM using the reference $4 \mathrm{C}$ model, with those obtained by the $2 \mathrm{C}$ and $3 \mathrm{C}$ models plus SA (FFM, FM and skinfolds sum of eight). These statistics included the difference in the mean between measurements, typical error and confidence limits. The typical error, equivalent to the technical error of measurement in this study, was inferred by test-retest technical variation $\left(\mathrm{D}_{1} \mathrm{~T}_{1}\right.$ and $\left.\mathrm{D}_{1} \mathrm{~T}_{2}\right)$ and from within-subject biological error from morning to afternoon $\left(\mathrm{D}_{1} \mathrm{~T}_{1}\right.$ and $\left.\mathrm{D}_{1} \mathrm{~T}_{3}\right)$, from day 1 to day $2\left(\mathrm{D}_{1} \mathrm{~T}_{1}\right.$ and $\left.\mathrm{D}_{2} \mathrm{~T}_{4}\right)$, and from before to after the meal $\left(\mathrm{D}_{2} \mathrm{~T}_{4}\right.$ and $\left.\mathrm{D}_{2} \mathrm{~T}_{5}\right)$. For all conditions, this was expressed as a CV. The determination of smallest worthwhile effect from differences in the means was calculated after the difference was standardised by dividing by the standard deviation (Cohen's effect size). To ensure the smallest worthwhile differences in body composition were standardised, one-third of the between-subjects standard deviation was used for standardising ( $\Delta$ Mean/ $(1 / 3 \times \mathrm{SD}))^{(10)}$. This is because the large standard deviation between-subjects were approximately three times greater than those previously discovered in a study using an athletic cohort $^{(27)}$. Therefore, the magnitudes of standardised effects were categorised as follows: $<0.20$ trivial, $<0.60$ small, $<1.20$ moderate and $<2.0$ large ${ }^{(28)}$. The typical errors were deemed as substantial for the smallest worthwhile effect when the standardised value reached the tolerance for a small effect $(\geq 0 \cdot 2)^{(18)}$.

\section{Results}

\section{Technical variation from standardised presentation}

The change in the mean of repeated measurements $\left(D_{1} T_{1}\right.$ and $\mathrm{D}_{1} \mathrm{~T}_{2}$ ) in all methods for estimates of $\mathrm{BM}(\mathrm{kg})$, TBW (L), skinfolds (mm), FFM (kg) and FM (kg) to infer technical variation were trivial (Fig. 2). Typical errors associated with estimates of all values were also trivial except for TBW and the 3C model (FM) which were small, BOD POD (FM) and 4C model (FM) which were moderately larger, and BIS (FM) which was substantially larger, than the smallest worthwhile effect (Table 2).

\section{Biological variation from non-standardised presentation}

The change in the mean of within-day biological variation $\left(D_{1} T_{1}\right.$ and $\mathrm{D}_{1} \mathrm{~T}_{3}$ ) in SA (mm), SA (FFM), BOD POD (FFM, FM) and DXA (FM) were trivial but for BM and DXA (FFM) there was a small change from the smallest worthwhile effect (1 and $1.2 \%$ respectively). For TBW, BIS (FFM, FM), 3C and 4C models (FFM, FM) and SA (FM) there were large changes in the mean from the smallest worthwhile effect. Trivial typical errors were evident for BM, SA (mm, FFM), BOD POD (FFM), 3C and $4 \mathrm{C}$ models (FFM) and DXA (FM) but a small typical error was found in DXA (FFM). Moderately large typical errors were identified in TBW and BIS (FFM) whereas BOD POD (FM), BIS (FM), 3C and 4C models (FM) and SA (FM) had substantially larger typical errors from the smallest worthwhile effect (Table 3).

\section{Biological variation from standardised presentation}

The change in the mean of biological variation in between-day estimates $\left(D_{1} T_{1}\right.$ and $\left.D_{2} T_{4}\right)$ were trivial in all methods for all raw 
values, FFM, FM estimations except for BIS (FM) where there was a substantially large change from the smallest worthwhile effect (Table 4). There were trivial typical errors associated with
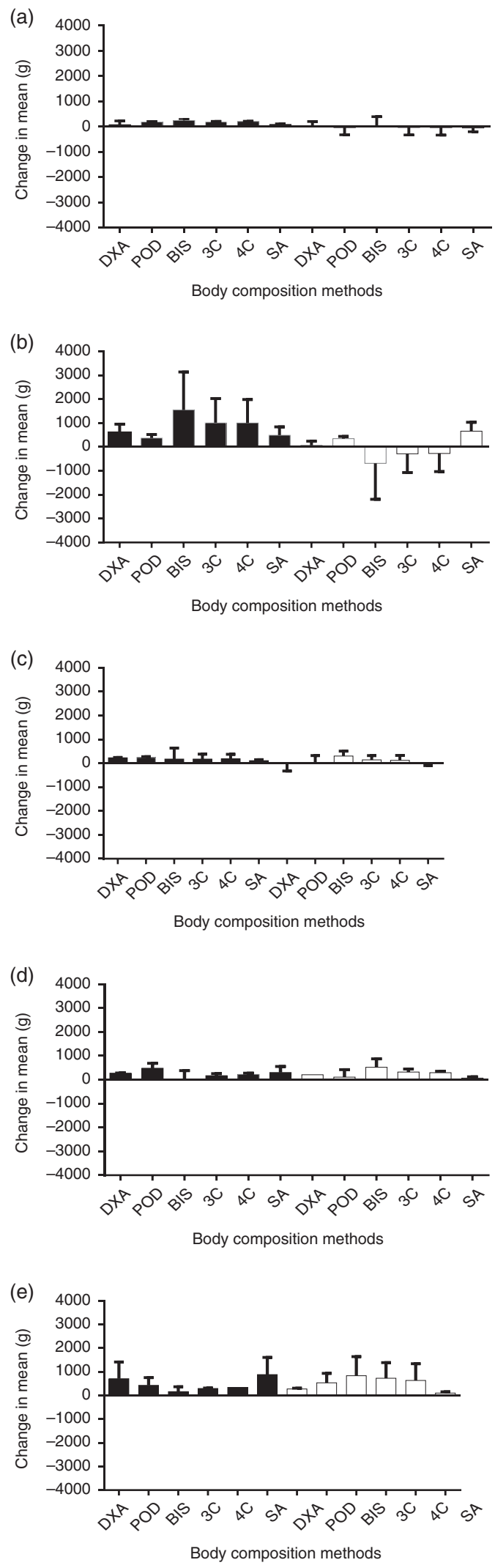

estimates of BM (kg), SA (mm, FFM, FM), DXA (FFM) and BOD POD (FFM). Small typical errors were found in DXA (FM), 3C and $4 \mathrm{C}$ models (FFM) whereas moderate errors were identified in TBW, BIS (FFM) and BOD POD (FM). Finally, BIS (FM), 3C and $4 \mathrm{C}$ models (FM) all produced larger typical errors than the smallest worthwhile effect (Table 4).

\section{Biological variation from ingestion of a $500 \mathrm{~g}$ meal}

The change in the mean of measurement $\left(\mathrm{D}_{2} \mathrm{~T}_{4}\right.$ and $\left.\mathrm{D}_{2} \mathrm{~T}_{5}\right)$ after ingestion of a $500 \mathrm{~g}$ meal for all body composition estimates was trivial except for BOD POD (FFM) with a small change and BIS (FM) with a substantially large change, from the smallest worthwhile effect. Typical errors that were substantially larger than the smallest worthwhile effect were identified in BOD POD (FM) and BIS (FM) whereas BM and all body composition estimates by the other methods were trivial (Table 5).

\section{Biological variation from ingestion of a $500 \mathrm{~g}$ meal plus 1 litre of water}

There were trivial changes in the mean of the measurements $\left(\mathrm{D}_{2} \mathrm{~T}_{4}\right.$ and $\left.\mathrm{D}_{2} \mathrm{~T}_{5}\right)$ after ingestion of a $500 \mathrm{~g}$ meal plus 1 litre of water for all methods for body composition estimates except BM, DXA (FFM) and SA (FFM) with a moderately larger change, and substantially larger change in BOD POD (FM), BIS (FM), 3C and $4 \mathrm{C}$ models (FM), than the smallest worthwhile effect (Table 5). The typical errors for all methods after ingestion of the $500 \mathrm{~g}$ meal plus 1 litre of water were trivial for body composition estimates except BOD POD (FM) and BIS (FM) with moderately large errors from the smallest worthwhile effect.

\section{Discussion}

The key findings of this study were that biological variables such as TBW, acute food and fluid intake and physical activity had a substantially large impact upon 2C, 3C and 4C models of body composition assessment. When a standardised subject presentation (overnight fasted, rested, consistent hydration) and quality control protocols were implemented the change in the mean of the measurements was trivial except for BIS (FM). However, the typical errors in testing under these conditions varied from small to substantially large especially for FM. For non-standardised presentation testing the change in the mean of the measurements and typical errors were mostly moderately or substantially large from the smallest worthwhile effect for all estimates in all techniques. Furthermore, the ingestion of a meal

Fig. 2. Reliability results - change in mean and $90 \%$ Cl. (a) Standardised presentation test retest reliability - test 1 v. 2; (b) non-standardised presentation reliability - test 1 v. 3; (c) standardised presentation between-day reliability - test 1 v. 4 ; (d) impact of $500 \mathrm{~g}$ meal on reliability - test 4 v. 5; (e) impact of $500 \mathrm{~g} \mathrm{meal}+1000 \mathrm{~g} \mathrm{H}_{2} \mathrm{O}$ on reliability - test 4 v. 5 . DXA, dualenergy X-ray absorptiometry; POD, air displacement plethysmography; BIS, bioelectrical impedance spectroscopy; $3 \mathrm{C}$, three compartment model; $4 \mathrm{C}$, four compartment model; SA, surface anthropometry; $\square$, fat-free mass; $\square$, fat mass. 
Table 2. Test-retest change in mean ( $\Delta$ Mean) and technical error in standardised presentation testing (Mean values and standard deviations; percentages and absolute measures)

\begin{tabular}{|c|c|c|c|c|c|c|c|c|}
\hline & & & & & \multicolumn{4}{|c|}{ Day 1 , test $1 v$. day 1 , test 2} \\
\hline & \multicolumn{2}{|c|}{$n 32$} & \multicolumn{2}{|c|}{ SWE } & \multicolumn{2}{|c|}{$\Delta$ Mean } & \multicolumn{2}{|c|}{ TEM } \\
\hline & Mean & SD & $\%$ & Absolute & $\%$ & Absolute & $\%$ & Absolute \\
\hline \multicolumn{9}{|l|}{ Raw data } \\
\hline Body mass & $91.6 \mathrm{~kg}$ & $10 \cdot 1$ & 0.7 & $660 \mathrm{~g}$ & -0.1 & $-50 \mathrm{~g}$ & 0.1 & $50 \mathrm{~g}$ \\
\hline SA & $81.7 \mathrm{~mm}$ & 30.4 & 2.5 & $2 \mathrm{~mm}$ & $-1 \cdot 1$ & $-1.0 \mathrm{~mm}$ & 0.8 & $0.8 \mathrm{~mm}$ \\
\hline TBW & 57.3 litre & $5 \cdot 8$ & 0.7 & $380 \mathrm{ml}$ & 0.2 & $140 \mathrm{ml}$ & $0.8 \dagger$ & $480 \mathrm{ml}$ \\
\hline \multicolumn{9}{|l|}{ FFM } \\
\hline DXA & $74.7 \mathrm{~kg}$ & $7 \cdot 6$ & 0.7 & $512 \mathrm{~g}$ & 0.0 & $-33 g$ & 0.6 & $434 \mathrm{~g}$ \\
\hline BOD POD & $74.8 \mathrm{~kg}$ & 7.5 & 0.7 & $503 \mathrm{~g}$ & 0.2 & $196 \mathrm{~g}$ & 0.5 & $407 \mathrm{~g}$ \\
\hline BIS & $78.2 \mathrm{~kg}$ & 7.9 & 0.7 & $520 \mathrm{~g}$ & 0.2 & $197 \mathrm{~g}$ & 0.8 & $661 \mathrm{~g}$ \\
\hline $3 C$ & $76.4 \mathrm{~kg}$ & 7.5 & 0.7 & $500 \mathrm{~g}$ & 0.3 & $199 \mathrm{~g}$ & 0.5 & $433 \mathrm{~g}$ \\
\hline $4 \mathrm{C}$ & $76.4 \mathrm{~kg}$ & $7 \cdot 6$ & 0.7 & $505 \mathrm{~g}$ & 0.3 & $205 \mathrm{~g}$ & 0.5 & $442 \mathrm{~g}$ \\
\hline SA & $80.5 \mathrm{~kg}$ & $8 \cdot 2$ & 0.7 & $534 \mathrm{~g}$ & $0 \cdot 1$ & $100 \mathrm{~g}$ & 0.2 & $160 \mathrm{~g}$ \\
\hline \multicolumn{9}{|l|}{ FM } \\
\hline DXA & $17 \cdot 1 \mathrm{~kg}$ & 6.9 & $2 \cdot 9$ & $496 \mathrm{~g}$ & -0.3 & $-96 g$ & 1.9 & $351 \mathrm{~g}$ \\
\hline BOD POD & $16 \cdot 8 \mathrm{~kg}$ & $6 \cdot 4$ & $2 \cdot 6$ & $431 \mathrm{~g}$ & $-2 \cdot 0$ & $-242 \mathrm{~g}$ & $3.4 \ddagger$ & $393 \mathrm{~g}$ \\
\hline BIS & $13.3 \mathrm{~kg}$ & $7 \cdot 2$ & 4.7 & $622 \mathrm{~g}$ & $-1 \cdot 1$ & $-253 \mathrm{~g}$ & $8.7 \S$ & $668 \mathrm{~g}$ \\
\hline $3 C$ & $15 \cdot 2 \mathrm{~kg}$ & $6 \cdot 7$ & $3 \cdot 2$ & $484 \mathrm{~g}$ & $-1 \cdot 8$ & $-244 \mathrm{~g}$ & $3.7 \dagger$ & $426 \mathrm{~g}$ \\
\hline $4 \mathrm{C}$ & $15 \cdot 2 \mathrm{~kg}$ & $6 \cdot 7$ & 3.2 & $483 \mathrm{~g}$ & -1.9 & $-250 \mathrm{~g}$ & $4.0 \ddagger$ & $432 \mathrm{~g}$ \\
\hline SA & $11.0 \mathrm{~kg}$ & $4 \cdot 2$ & $2 \cdot 5$ & $270 \mathrm{~g}$ & $-1 \cdot 3$ & $-160 \mathrm{~g}$ & 0.9 & $130 \mathrm{~g}$ \\
\hline
\end{tabular}

SWE, smallest worthwhile effect; TEM, typical error of measurement expressed as a CV (\%) and absolute units (g, mm, ml); SA, surface anthropometry; TBW, total body water; FFM, fat-free mass; DXA, dual-energy X-ray absorptiometry; BOD POD, air displacement plethysmography; BIS, bioelectrical impedance spectroscopy; $3 C$, three compartment model; 4C, four compartment model; FM, fat mass.

* Mean values and standard deviations taken from first testing session.

$\dagger$ Small value of $\triangle$ Mean or TEM.

$\ddagger$ Moderate value of $\triangle$ Mean or TEM.

$\S$ Large value of $\triangle$ Mean or TEM.

Table 3. Biological error and change in mean ( $\Delta$ Mean) in non-standardised presentation testing

(Mean values and standard deviations; percentages and absolute measures)

\begin{tabular}{|c|c|c|c|c|c|c|c|c|}
\hline & & & & & \multicolumn{4}{|c|}{ Day 1 , test $1 v$. day 1 , test 3} \\
\hline & \multicolumn{2}{|c|}{$n 32$} & \multicolumn{2}{|c|}{ SWE } & \multicolumn{2}{|c|}{$\Delta$ Mean } & \multicolumn{2}{|c|}{ TEM } \\
\hline & Mean* & SD & $\%$ & Absolute & $\%$ & Absolute & $\%$ & Absolute \\
\hline \multicolumn{9}{|l|}{ Raw data } \\
\hline Body mass & $91.6 \mathrm{~kg}$ & $10 \cdot 1$ & 0.7 & $660 \mathrm{~g}$ & $1.0 \dagger$ & $890 \mathrm{~g}$ & 0.7 & $640 \mathrm{~g}$ \\
\hline SA & $81.7 \mathrm{~mm}$ & $30 \cdot 4$ & $2 \cdot 5$ & $2 \mathrm{~mm}$ & 0.8 & $0.6 \mathrm{~mm}$ & 1.4 & $1.2 \mathrm{~mm}$ \\
\hline TBW & 57.3 litre & $5 \cdot 8$ & 0.4 & $664 \mathrm{ml}$ & $3.4 \ddagger$ & $1960 \mathrm{ml}$ & $1.2 \S$ & $720 \mathrm{ml}$ \\
\hline \multicolumn{9}{|l|}{ FFM } \\
\hline DXA & $74.7 \mathrm{~kg}$ & 7.6 & 0.7 & $527 \mathrm{~g}$ & $1.2 \dagger$ & $847 \mathrm{~g}$ & $1.1 \dagger$ & $786 \mathrm{~g}$ \\
\hline BOD POD & $74.8 \mathrm{~kg}$ & 7.5 & 0.7 & $503 \mathrm{~g}$ & 0.6 & $480 \mathrm{~g}$ & 0.9 & $644 \mathrm{~g}$ \\
\hline BIS & $78.2 \mathrm{~kg}$ & 7.9 & 0.7 & $520 \mathrm{~g}$ & $3.4 \ddagger$ & $2677 \mathrm{~g}$ & $1 \cdot 2 \S$ & $987 \mathrm{~g}$ \\
\hline $3 C$ & $76.4 \mathrm{~kg}$ & 7.5 & 0.7 & $500 \mathrm{~g}$ & $2 \cdot 3 \neq$ & $1733 \mathrm{~g}$ & 0.9 & $717 \mathrm{~g}$ \\
\hline $4 \mathrm{C}$ & $76.4 \mathrm{~kg}$ & $7 \cdot 6$ & 0.7 & $505 \mathrm{~g}$ & $2 \cdot 2 \ddagger$ & $1701 \mathrm{~g}$ & 0.9 & $735 \mathrm{~g}$ \\
\hline SA & $80.5 \mathrm{~kg}$ & 8.2 & 0.7 & $534 \mathrm{~g}$ & 0.9 & $740 \mathrm{~g}$ & 0.7 & $590 \mathrm{~g}$ \\
\hline \multicolumn{9}{|l|}{$\mathrm{FM}$} \\
\hline DXA & $17 \cdot 1 \mathrm{~kg}$ & 6.9 & 2.9 & $496 \mathrm{~g}$ & 0.5 & $-54 \mathrm{~g}$ & 3.1 & $455 \mathrm{~g}$ \\
\hline BOD POD & $16.8 \mathrm{~kg}$ & 6.4 & 2.6 & $431 \mathrm{~g}$ & $2 \cdot 8$ & $414 \mathrm{~g}$ & $4.8 \ddagger$ & $653 \mathrm{~g}$ \\
\hline BIS & $13.3 \mathrm{~kg}$ & $7 \cdot 2$ & 4.7 & $622 \mathrm{~g}$ & $-15 \cdot 1 \ddagger$ & $-1749 g$ & $9 \cdot 0 \ddagger$ & $879 \mathrm{~g}$ \\
\hline $3 C$ & $15 \cdot 2 \mathrm{~kg}$ & 6.7 & 3.2 & $484 \mathrm{~g}$ & $-6 \cdot 9 \ddagger$ & $-840 \mathrm{~g}$ & $8.9 \ddagger$ & $631 \mathrm{~g}$ \\
\hline $4 \mathrm{C}$ & $15 \cdot 2 \mathrm{~kg}$ & $6 \cdot 7$ & 3.2 & $483 \mathrm{~g}$ & $-6 \cdot 7 \ddagger$ & $-807 \mathrm{~g}$ & $9 \cdot 6 \ddagger$ & $631 \mathrm{~g}$ \\
\hline SA & $11.0 \mathrm{~kg}$ & $4 \cdot 2$ & 2.5 & $270 \mathrm{~g}$ & $10.4 \ddagger$ & $930 \mathrm{~g}$ & $8.6 \ddagger$ & $950 \mathrm{~g}$ \\
\hline
\end{tabular}

SWE, smallest worthwhile effect; TEM, typical error of measurement expressed as a CV (\%) and absolute units ( $\mathrm{g}, \mathrm{mm}, \mathrm{ml})$; SA, surface anthropometry; TBW, total body water; FFM, fat-free mass; DXA, dual-energy X-ray absorptiometry; BOD POD, air displacement plethysmography; BIS, bioelectrical impedance spectroscopy; $3 \mathrm{C}$, three compartment model; 4C, four compartment model; FM, fat mass.

* Mean and standard deviations taken from first testing session.

$\dagger$ Small value of $\triangle$ Mean or TEM.

$\mp$ Moderate value of $\triangle$ Mean or TEM.

$\S$ Large value of $\triangle$ Mean or TEM. 
Table 4. Biological error and change in mean ( $\Delta$ Mean) in between-day standardised presentation testing (Mean values and standard deviations; percentages and absolute measures)

\begin{tabular}{|c|c|c|c|c|c|c|c|c|}
\hline & & & & & \multicolumn{4}{|c|}{ Day 1 , test $1 v$. day 2 , test 4} \\
\hline & \multicolumn{2}{|c|}{$n 32$} & \multicolumn{2}{|c|}{ SWE } & \multicolumn{2}{|c|}{$\Delta$ Mean } & \multicolumn{2}{|c|}{ TEM } \\
\hline & Mean* & $\mathrm{SD}$ & $\%$ & Absolute & $\%$ & Absolute & $\%$ & Absolute \\
\hline \multicolumn{9}{|l|}{ Raw data } \\
\hline Body mass & $91.6 \mathrm{~kg}$ & $10 \cdot 1$ & 0.7 & $660 \mathrm{~g}$ & 0.0 & $40 \mathrm{~g}$ & 0.4 & $370 \mathrm{~g}$ \\
\hline SA & $81.7 \mathrm{~mm}$ & $30 \cdot 4$ & 2.5 & $2 \mathrm{~mm}$ & -0.6 & $-0.5 \mathrm{~mm}$ & 1.0 & $0.8 \mathrm{~mm}$ \\
\hline TBW & $57 \cdot 3$ litre & $5 \cdot 8$ & 0.4 & $664 \mathrm{ml}$ & -0.3 & $-110 \mathrm{ml}$ & $1.5 \dagger$ & $860 \mathrm{ml}$ \\
\hline \multicolumn{9}{|l|}{ FFM } \\
\hline DXA & $74.7 \mathrm{~kg}$ & $7 \cdot 6$ & 0.7 & $527 \mathrm{~g}$ & 0.3 & $217 \mathrm{~g}$ & 0.7 & $563 \mathrm{~g}$ \\
\hline BOD POD & $74.8 \mathrm{~kg}$ & $7 \cdot 5$ & 0.7 & $503 \mathrm{~g}$ & 0.4 & $266 \mathrm{~g}$ & 0.7 & $529 \mathrm{~g}$ \\
\hline BIS & $78.2 \mathrm{~kg}$ & $7 \cdot 9$ & 0.7 & $520 \mathrm{~g}$ & -0.3 & $-153 g$ & $1.5 \dagger$ & $1173 \mathrm{~g}$ \\
\hline $3 C$ & $76.4 \mathrm{~kg}$ & $7 \cdot 5$ & 0.7 & $500 \mathrm{~g}$ & 0.0 & $28 \mathrm{~g}$ & $1.0 \ddagger$ & $748 \mathrm{~g}$ \\
\hline $4 C$ & $76.4 \mathrm{~kg}$ & $7 \cdot 6$ & 0.7 & $505 \mathrm{~g}$ & 0.0 & $58 \mathrm{~g}$ & $1.0 \ddagger$ & $745 \mathrm{~g}$ \\
\hline SA & $80.5 \mathrm{~kg}$ & $8 \cdot 2$ & 0.7 & $534 \mathrm{~g}$ & 0.1 & $80 \mathrm{~g}$ & 0.4 & $340 \mathrm{~g}$ \\
\hline \multicolumn{9}{|l|}{$\mathrm{FM}$} \\
\hline DXA & $17 \cdot 1 \mathrm{~kg}$ & 6.9 & 2.9 & $496 \mathrm{~g}$ & -0.8 & $-235 g$ & $3 \cdot 2 \ddagger$ & $449 \mathrm{~g}$ \\
\hline BOD POD & $16 \cdot 8 \mathrm{~kg}$ & $6 \cdot 4$ & $2 \cdot 6$ & $431 \mathrm{~g}$ & $-1 \cdot 3$ & $-228 g$ & $3.6 \dagger$ & $554 \mathrm{~g}$ \\
\hline BIS & $13.3 \mathrm{~kg}$ & $7 \cdot 2$ & $4 \cdot 7$ & $622 \mathrm{~g}$ & $6 \cdot 2 \S$ & $162 \mathrm{~g}$ & $14.9 \S$ & $1065 \mathrm{~g}$ \\
\hline $3 C$ & $15 \cdot 2 \mathrm{~kg}$ & $6 \cdot 7$ & $3 \cdot 2$ & $484 \mathrm{~g}$ & 1.6 & $10 \mathrm{~g}$ & $5 \cdot 4 \S$ & $629 \mathrm{~g}$ \\
\hline $4 C$ & $15 \cdot 2 \mathrm{~kg}$ & $6 \cdot 7$ & $3 \cdot 2$ & $483 \mathrm{~g}$ & 1.4 & $-20 \mathrm{~g}$ & $5 \cdot 1 \S$ & $629 \mathrm{~g}$ \\
\hline SA & $11.0 \mathrm{~kg}$ & $4 \cdot 2$ & 2.5 & $270 \mathrm{~g}$ & -0.6 & $-70 \mathrm{~g}$ & $1 \cdot 1$ & $120 \mathrm{~g}$ \\
\hline
\end{tabular}

SWE, smallest worthwhile effect; TEM, typical error of measurement expressed as a CV (\%) and absolute units (g, mm, ml); SA, surface anthropometry; TBW, total body water; FFM, fat-free mass; DXA, dual-energy X-ray absorptiometry; BOD POD, air displacement plethysmography; BIS, bioelectrical impedance spectroscopy; 3 , three compartment model; 4C, four compartment model; FM, fat mass.

* Mean values and standard deviations taken from first testing session.

$\dagger$ Moderate value of $\triangle$ Mean or TEM.

$\ddagger$ Small value of $\triangle$ Mean or TEM.

$\S$ Large value of $\triangle$ Mean or TEM.

( $500 \mathrm{~g}$ or $500 \mathrm{~g}$ plus 1 litre of water) increased the errors of measurement in BM, DXA (FFM), SA (FFM) and BOD POD, BIS, $3 \mathrm{C}$ and $4 \mathrm{C}$ models (FM) for these values whereas a $500 \mathrm{~g}$ meal had a trivial effect on DXA (FFM, FM) and BOD POD (FFM, FM). Therefore, standardised presentation can minimise biological variables, the biggest contributor to measurement error. If reliable measures of FM and FFM are required, then DXA and BOD POD are suitable methods of assessment if standardised presentation is not possible.

\section{Surface anthropometry}

Of all the body composition assessment methods, only SA (mm) was reliable throughout all conditions including after daily activities or after ingesting a meal. In agreement, the effect of hypohydration and hyperhydration on skinfold measurements has been found to be insignificant ${ }^{(29)}$ suggesting that SA is robust and unaffected by changes in hydration status. However, the technique of SA typically involves the measure of $\mathrm{BM}$, a variable acutely influenced by a range of factors including hydration status, gastrointestinal tract contents and muscle glycogen stores ${ }^{(15)}$. To counter such variance, the protocol of athlete presentation for SA should follow previous recommendations of overnight fasted, post bladder and bowel evacuation with body mass measurements taken in minimal clothing ${ }^{(30)}$. Nonetheless, despite being very robust, SA fails to provide an absolute measure of FM and FFM which is available through other $2 \mathrm{C}, 3 \mathrm{C}$ and $4 \mathrm{C}$ models. In addition, regression equations used to estimate \%BF are not validated to track changes in body composition $^{(31)}$.

\section{Air displacement plethysmography}

BOD POD measures body density and provides estimates of FM and FFM via a $2 \mathrm{C}$ model using the Siri equation ${ }^{(3)}$ and guidance published by the manufacturer recommends a 2-h fast and exercise free period before testing to minimise biological error. Previous research using BOD POD technology provide results consistent with this study, with only trivial typical errors in FFM estimates from between-day testing conducted under a standardised presentation ${ }^{(17)}$. Presenting in a dehydrated state for body composition assessment via a $2 \mathrm{C}$ model may introduce error $^{(8)}$, and dehydration in BOD POD assessments has produced a small underestimation in body fat $(1 \cdot 1 \%)$ which may be important when tracking longitudinal change ${ }^{(17)}$. Our study showed that when food, fluid and physical activities are unrestricted before testing, FM estimations from BOD POD are subject to large typical errors $(653 \mathrm{~g}$ ). Ingestion of $1000 \mathrm{ml}$ of fluid before body composition assessment by BOD POD increased body fat measures by $1 \cdot 1 \%^{(13)}$ and a meal of $500 \mathrm{~g}$ plus 1 litre of water resulted in measurement errors of $660 \mathrm{~g}$ (FFM) and $820 \mathrm{~g}$ (FM). In contrast, a smaller $500 \mathrm{~g}$ meal produced only a small change in the mean for FFM and a trivial change for FM, suggesting that reliability of assessment is possible with either a standardised presentation or prior ingestion of a specified $(<500 \mathrm{~g})$ meal.

\section{Dual-energy X-ray absorptiometry}

DXA, a $2 \mathrm{C}$ model, provides estimates of FM and FFM via attenuation of two photons of light (X-rays) through body tissue 
Table 5. Biological error and change in mean ( $\Delta$ Mean) from ingestion of meal after standardised presentation testing (Mean values and standard deviations; percentages and absolute measures)

\begin{tabular}{|c|c|c|c|c|c|c|c|c|c|}
\hline & \multirow[b]{3}{*}{ Meal (kg) } & & & \multirow{2}{*}{\multicolumn{2}{|c|}{ SWE }} & \multicolumn{4}{|c|}{ Day 2 , test $4 v$. day 2 , test 5} \\
\hline & & \multicolumn{2}{|c|}{$n 16$} & & & \multicolumn{2}{|c|}{$\Delta$ Mean } & \multicolumn{2}{|c|}{ TEM } \\
\hline & & Mean* & SD & $\%$ & Absolute & $\%$ & Absolute & $\%$ & Absolute \\
\hline \multicolumn{10}{|l|}{ Raw data } \\
\hline \multirow[t]{2}{*}{ Body mass } & 0.5 & $90.5 \mathrm{~kg}$ & $7 \cdot 6$ & 0.5 & $494 \mathrm{~g}$ & 0.6 & $524 \mathrm{~g}$ & 0.0 & $20 \mathrm{~g}$ \\
\hline & 1.5 & $92.7 \mathrm{~kg}$ & $12 \cdot 3$ & 0.9 & $812 \mathrm{~g}$ & $1.6 \dagger$ & $1480 \mathrm{~g}$ & 0.2 & $80 \mathrm{~g}$ \\
\hline \multirow[t]{2}{*}{ SA } & 0.5 & $85.0 \mathrm{~mm}$ & $25 \cdot 7$ & $2 \cdot 1$ & $1.8 \mathrm{~mm}$ & -0.7 & $0.5 \mathrm{~mm}$ & 0.8 & $0.7 \mathrm{~mm}$ \\
\hline & 1.5 & $77.5 \mathrm{~mm}$ & 34.5 & $2 \cdot 8$ & $2.2 \mathrm{~mm}$ & -0.9 & $-0.6 \mathrm{~mm}$ & 1.0 & $0.8 \mathrm{~mm}$ \\
\hline \multirow[t]{2}{*}{ TBW } & 0.5 & 56.7 litre & $5 \cdot 3$ & 0.6 & $344 \mathrm{ml}$ & -0.4 & $-200 \mathrm{ml}$ & 0.5 & $320 \mathrm{ml}$ \\
\hline & 1.5 & 57.6 litre & 6.9 & 0.7 & $424 \mathrm{ml}$ & 0.0 & $10 \mathrm{ml}$ & 0.7 & $400 \mathrm{ml}$ \\
\hline \multicolumn{10}{|l|}{ FFM } \\
\hline \multirow[t]{2}{*}{ DXA } & 0.5 & $73.0 \mathrm{~kg}$ & $7 \cdot 0$ & 0.6 & $471 \mathrm{~g}$ & 0.4 & $277 \mathrm{~g}$ & 0.6 & $448 \mathrm{~g}$ \\
\hline & 1.5 & $76.8 \mathrm{~kg}$ & 8.4 & 0.7 & $539 \mathrm{~g}$ & $1.6 \dagger$ & $1211 \mathrm{~g}$ & 0.5 & $334 \mathrm{~g}$ \\
\hline \multirow[t]{2}{*}{ BOD POD } & 0.5 & $73.7 \mathrm{~kg}$ & $6 \cdot 2$ & 0.6 & $413 \mathrm{~g}$ & $0.9 \ddagger$ & $630 \mathrm{~g}$ & 0.7 & $538 \mathrm{~g}$ \\
\hline & 1.5 & $76.4 \mathrm{~kg}$ & 8.6 & 0.8 & $591 \mathrm{~g}$ & 0.8 & $660 \mathrm{~g}$ & 0.6 & $498 \mathrm{~g}$ \\
\hline \multirow[t]{2}{*}{ BIS } & 0.5 & $77.5 \mathrm{~kg}$ & $7 \cdot 2$ & 0.6 & $470 \mathrm{~g}$ & -0.4 & $-268 g$ & 0.5 & $435 \mathrm{~g}$ \\
\hline & 1.5 & $78.7 \mathrm{~kg}$ & 9.5 & 0.7 & $579 \mathrm{~g}$ & 0.0 & $12 \mathrm{~g}$ & 0.7 & $544 \mathrm{~g}$ \\
\hline \multirow[t]{2}{*}{$3 C$} & 0.5 & $75.5 \mathrm{~kg}$ & 6.6 & 0.6 & $433 \mathrm{~g}$ & 0.1 & $112 \mathrm{~g}$ & 0.5 & $377 \mathrm{~g}$ \\
\hline & 1.5 & $77.4 \mathrm{~kg}$ & 8.9 & 0.7 & $572 \mathrm{~g}$ & 0.4 & $286 \mathrm{~g}$ & 0.5 & $406 \mathrm{~g}$ \\
\hline \multirow[t]{2}{*}{$4 \mathrm{C}$} & 0.5 & $75.4 \mathrm{~kg}$ & $6 \cdot 7$ & 0.6 & $439 \mathrm{~g}$ & 0.2 & $190 \mathrm{~g}$ & 0.5 & $410 \mathrm{~g}$ \\
\hline & 1.5 & $77.5 \mathrm{~kg}$ & 8.9 & 0.8 & $601 \mathrm{~g}$ & 0.4 & $340 \mathrm{~g}$ & 0.5 & $430 \mathrm{~g}$ \\
\hline \multirow[t]{2}{*}{ SA } & 0.5 & $79.2 \mathrm{~kg}$ & $7 \cdot 3$ & 0.5 & $412 \mathrm{~g}$ & 0.6 & $480 \mathrm{~g}$ & 0.2 & $190 \mathrm{~g}$ \\
\hline & 1.5 & $82.3 \mathrm{~kg}$ & 11.8 & 0.8 & $9612 \mathrm{~g}$ & $1.7 \dagger$ & $1400 \mathrm{~g}$ & 0.2 & $230 \mathrm{~g}$ \\
\hline \multicolumn{10}{|l|}{ FM } \\
\hline \multirow[t]{2}{*}{ DXA } & 0.5 & $17.5 \mathrm{~kg}$ & 6.4 & 2.5 & $439 \mathrm{~g}$ & 1.1 & $209 \mathrm{~g}$ & 1.7 & $340 \mathrm{~g}$ \\
\hline & 1.5 & $16 \cdot 1 \mathrm{~kg}$ & $7 \cdot 0$ & 3.3 & $541 \mathrm{~g}$ & $2 \cdot 1$ & $302 \mathrm{~g}$ & $2 \cdot 0$ & $321 \mathrm{~g}$ \\
\hline \multirow[t]{2}{*}{ BOD POD } & 0.5 & $16 \cdot 8 \mathrm{~kg}$ & $5 \cdot 7$ & $2 \cdot 2$ & $364 \mathrm{~g}$ & $-1 \cdot 2$ & $-106 g$ & $3.5 \S$ & $529 \mathrm{~g}$ \\
\hline & 1.5 & $16.4 \mathrm{~kg}$ & 7.0 & 3.0 & $502 \mathrm{~g}$ & $5.7 \S$ & $820 \mathrm{~g}$ & $3.9 \dagger$ & $497 \mathrm{~g}$ \\
\hline \multirow[t]{2}{*}{ BIS } & 0.5 & $12.9 \mathrm{~kg}$ & 6.4 & 3.5 & $457 \mathrm{~g}$ & $7 \cdot 1 \S$ & $774 \mathrm{~g}$ & $5.4 \S$ & $440 \mathrm{~g}$ \\
\hline & 1.5 & $13.9 \mathrm{~kg}$ & 7.0 & $5 \cdot 8$ & $780 \mathrm{~g}$ & $12.5 \S$ & $1407 \mathrm{~g}$ & $6.7 \dagger$ & $596 \mathrm{~g}$ \\
\hline \multirow[t]{2}{*}{$3 C$} & 0.5 & $15.0 \mathrm{~kg}$ & 5.9 & $2 \cdot 6$ & $388 \mathrm{~g}$ & $2 \cdot 7$ & $412 \mathrm{~g}$ & 2.5 & $369 \mathrm{~g}$ \\
\hline & 1.5 & $15.4 \mathrm{~kg}$ & 6.9 & 3.8 & $582 \mathrm{~g}$ & $8.8 \S$ & $1194 \mathrm{~g}$ & 3.3 & $408 \mathrm{~g}$ \\
\hline \multirow[t]{2}{*}{$4 C$} & 0.5 & $15 \cdot 1 \mathrm{~kg}$ & 5.9 & $2 \cdot 6$ & $392 \mathrm{~g}$ & $2 \cdot 1$ & $337 \mathrm{~g}$ & $2 \cdot 6$ & $405 \mathrm{~g}$ \\
\hline & 1.5 & $15 \cdot 2 \mathrm{~kg}$ & 6.9 & 3.4 & $518 \mathrm{~g}$ & $8.5 \S$ & $1137 \mathrm{~g}$ & 3.6 & $427 \mathrm{~g}$ \\
\hline \multirow[t]{2}{*}{ SA } & 0.5 & $11.1 \mathrm{~kg}$ & 0.2 & 2.0 & $226 \mathrm{~g}$ & 0.1 & $30 \mathrm{~g}$ & 1.4 & $190 \mathrm{~g}$ \\
\hline & 1.5 & $10.3 \mathrm{~kg}$ & 0.5 & 2.9 & $305 \mathrm{~g}$ & 0.6 & $60 \mathrm{~g}$ & 1.9 & $220 \mathrm{~g}$ \\
\hline
\end{tabular}

SWE, smallest worthwhile effect; TEM, typical error of measurement expressed as a CV (\%) and absolute units (g, mm, ml); SA, surface anthropometry; TBW, total body water; FFM, fat-free mass; DXA, dual-energy X-ray absorptiometry; BOD POD, air displacement plethysmography; BIS, bioelectrical impedance spectroscopy; $3 \mathrm{C}$, three compartment model; 4C, four compartment model; FM, fat mass.

* Mean values and standard deviations taken from first testing session.

† Moderate value of $\triangle$ Mean or TEM.

$\ddagger$ Small value of $\triangle$ Mean or TEM.

$\S$ Large value of $\triangle$ Mean or TEM.

depending on its composition. Manufacturing guidelines as well as previous research undertaken by our group recommend standardising both subject presentation and scan protocol ${ }^{(19)}$ in order to reduce biological and technical error. In this study, both the repeat tests and between-day testing under standardised conditions were very reliable for estimates of FFM using DXA technology. This is in agreement with previous literature reporting a $\mathrm{CV}$ of 0.5 and $1.5 \%$, respectively ${ }^{(32,10)}$. However, the DXA estimates of FM revealed a small typical error of $3.2 \%$ which is higher than previous studies investigating reliability of between-day standardised presentation testing $(2 \cdot 1 \%)^{(10,33,34)}$. In addition, DXA showed a trivial change in mean for FFM and FM for the $500 \mathrm{~g}$ post meal condition, whereas consumption of the larger meal $(500 \mathrm{~g}$ plus 1 litre of water) resulted in moderately substantial effect for FFM change in mean $(1211 \mathrm{~g})$. This suggests that DXA may be a suitable technique for reliable FM and FFM measurement if acute food and fluid intake is $<500 \mathrm{~g}$. However, ingesting a larger meal appears to influence biological error which, and in agreement with previous studies ${ }^{(11,35,36)}$ these results suggest that scans be conducted after an overnight fast.

\section{Bioelectrical impedance spectroscopy}

BIS is a doubly indirect measurement of body composition utilising complex algorithms to estimate FM and FFM from TBW estimations, therefore, the margin for biological error is much higher than for $\mathrm{D}_{2} \mathrm{O}$. Previous research using BIS has found that acute ingestion of fluid can overestimate FM by $3 \cdot 2 \%{ }^{(37)}$ and in agreement with this study, a $500 \mathrm{~g}$ meal increased the change in mean FM by $774 \mathrm{~g}$ whereas a larger meal (500 g meal plus 1 litre of water) increased FM by $1400 \mathrm{~g}$. Even small amounts of fluid intake $(590 \mathrm{ml})$ influences $\mathrm{FM}$ estimations ${ }^{(9)}$ so reliability of 
assessment is heavily dependent on subject presentation. In addition, the substantially large between-day biological error in FM and FFM estimates from BIS (1065 g, $1173 \mathrm{~g}$, respectively) suggests that caution must be applied when interpreting results from a single body composition assessment session despite standardised subject presentation and testing conditions. Finally, it was unsurprising to find that non-standardised presentation testing introduced substantial fluctuations in TBW, thus confounding BIS with FM estimations recording a large typical error $(879 \mathrm{~g})$ and a FFM change of mean score of $2677 \mathrm{~g}$. In light of these findings, it is recommended that subject presentation be meticulously standardised ${ }^{(38)}$ before utilising BIS technology.

\section{Three and four compartment models}

$\mathrm{D}_{2} \mathrm{O}$ is the reference method for laboratory-based TBW measurement in $3 \mathrm{C}$ and $4 \mathrm{C}$ models but is expensive and time consuming ${ }^{(39)}$. In contrast, BIS has been applied in both athlete and non-athletic populations being safe, non-invasive and cost effective with instantaneous TBW results ${ }^{(40)}$ that have been validated against $\mathrm{D}_{2} \mathrm{O}^{(5,41)}$. The $3 \mathrm{C}$ and $4 \mathrm{C}$ models in this study included measurements of TBW from BIS so intuitively we expected they would be highly influenced by these estimations. The slight fluctuation in TBW from repeat tests $\left(D_{1} T_{1}\right.$ and $\left.D_{1} T_{2}\right)$ suggests that there is inherent machine noise as daily respiratory water losses, typically $400 \mathrm{ml}^{(42)}$ could not occur this rapidly between repeat measurements. Consequently, the typical errors from 3C and 4C model estimates of FM appear to be influenced by the inclusion of TBW estimations in these models which is in agreement with the literature ${ }^{(1,43)}$. In addition, despite stable body mass, the moderately large typical error from TBW values (1.5\%) for between-day estimates $\left(D_{1} T_{1}\right.$ and $\mathrm{D}_{2} \mathrm{~T}_{4}$ ) indicates substantial variance which has influenced the FM and FFM estimates of the $3 \mathrm{C}(5.4 \%, 1.0 \%)$ and $4 \mathrm{C}$ models $(5.1 \%, 1.0 \%)$. Previous literature using the reference $\mathrm{D}_{2} \mathrm{O}$ technique found a within-day variability of TBW with night time crests ${ }^{(44)}$ so our results were not unexpected.

Large resistance trained athletic males such as the subjects in this study fluctuate widely in their hydration status due to training and recovery demands. So unsurprisingly there were substantial changes in the mean BM and TBW of 890 and $1960 \mathrm{~g}$, respectively, after non-standardised presentation testing. Therefore, FM estimations from $3 \mathrm{C}$ and $4 \mathrm{C}$ models were subject to large typical errors $(631 \mathrm{~g}, 631 \mathrm{~g})$. In addition, the large fluctuation in hydration also confounded $3 \mathrm{C}$ and $4 \mathrm{C}$ models for FFM estimates with mean change scores of 1733 and $1701 \mathrm{~g}$, respectively. Fluctuations in hydration would be expected to confound estimates of body composition using $3 \mathrm{C}$ and $4 \mathrm{C}$ values more than DXA because of the inclusion of body density values in these models. The concomitant change in the measures of density of the FFM associated with changes in TBW in turn confounds estimates of $\mathrm{FM}^{(34)}$.

In conclusion, models that included a measured TBW value from BIS (3C and 4C) were highly influenced by TBW fluctuations under non-standardised conditions than other 2C models. This means that any body composition assessment undertaken with non-standardised presentation of subjects will significantly increase biological error and thus, reduce accuracy.
As the 2C models assume a constant TBW of $73.7 \%$ this error may not be so obvious but our results of fluctuating BM, TBW and associated influence on FM and FFM under these conditions show otherwise. Therefore, biological error via acute TBW change in FFM is minimised in body composition assessment models if subjects present in an overnight fasted and rested state, with specific advice relating to optimisation of hydration status the day before assessment. Standardised presentation of subjects should be mandatory for all body composition assessment if reliable measures of FM and FFM are required. When circumstances prevent standardised presentation of subjects, then assessment via DXA and BOD POD is acceptable if acute food and fluid intake remains below $500 \mathrm{~g}$. Of all the methods of body composition assessment, only SA (mm) produced trivial errors across all conditions making it ideal for longitudinal assessment despite time of day or acute physical condition of subjects.

The limitations of this study include applying a BIS estimation of TBW instead of the reference method of $\mathrm{D}_{2} \mathrm{O}$ for TBW assessment which amplified biological error in $3 \mathrm{C}$ and $4 \mathrm{C}$ models. However, due to the timeframe required for $\mathrm{D}_{2} \mathrm{O}$ (4-6 h equilibrium time) this study design would not have been possible given the repeat nature of TBW assessment. Second, initial USG testing before $\mathrm{D}_{1} \mathrm{~T}_{1}$ and $\mathrm{D}_{2} \mathrm{~T}_{4}$, identified several subjects with a USG $>1 \cdot 020$, often used as a cut off for the identification of hypohydration ${ }^{(45)}$, which could possibly confound results. However, no exclusions were made because according to the literature USG specificity to detect hypohydration in athletes with large FFM, similar to those in this study, is reduced ${ }^{(46)}$. This may be a consequence of the positive relationship with muscle mass and urine protein metabolites and USG. Another potential limitation is that we do not know if the specified meal of $500 \mathrm{~g}$ would impact biological error in smaller size populations using DXA or BOD POD for assessment. The strengths of this investigation include new evidence that a standardised subject presentation can minimise biological error caused by acute food and fluid intake plus ad libitum activity. Furthermore, this reduction in error is robust despite between-day biological variability for all body composition assessment methods. Manufacturer's recommendations for BOD POD tests require only a 2 -h fast and exercise free period before testing and commercial use BIS only recommends avoiding excessive exercise $2 \mathrm{~h}$ prior and $12 \mathrm{~h}$ from excess alcohol consumption. DXA guidelines recommend overnight fasted presentation but in commercial practice this is rarely the case. The results of our study, especially for 3C and 4C models with an inclusion of TBW from BIS, clearly show biological error is particularly variable after ad libitum food/fluid and activity as well as after ingestion of an extra $1000 \mathrm{ml}$ of fluid.

\section{Acknowledgements}

The authors thank the subjects who kindly volunteered their time for this study.

This research received no specific grant from any funding agency, commercial or not-for-profit sectors.

The authors' responsibilities were as follows: A. K. and G. J. S.: study concept and design, analysis and interpretation of data; A. K.: acquisition of data, draft of manuscript, statistical 
analysis and had full access to all of the data in the study and takes responsibility for the integrity of the data and the accuracy of the data analysis; A. K., G. J. S. and N. B.: critical revision of the manuscript for important intellectual content; and G. J. S.: study supervision.

None of the authors has any conflicts of interest to declare.

\section{References}

1. Withers RT, Laforgia J \& Heymsfield SB (1999) Critical appraisal of the estimation of body composition via two-, three-, and four-compartment models. Am J Hum Biol 11, 175-185.

2. Brožek J, Grande F, Anderson JT, et al. (1963) Densitometric analysis of body composition: revision of some qantitative assumptions. Ann N Y Acad Sci 110, 113-140.

3. Siri WE (1961) Body composition from fluid spaces and density: analysis of methods. Nutrition 9, 480-491.

4. Santos DA, Silva AM, Matias CN, et al. (2011) Changes in fat-free mass composition and density in elite basketball players over an entire season. Int J Obes 35, S18.

5. Kerr A, Slater G, Byrne N, et al. (2015) Validation of bioelectrical impedance spectroscopy to measure total body water in resistance trained males. Int J Sport Nutr Exerc Metab 25, 494-503.

6. Wang J \& Pierson RN (1976) Disparate hydration of adipose and lean tissue require a new model for body water distribution in man. J Nutr 106, 1687-1693.

7. Withers RT, LaForgia J, Pillans RK, et al. (1998) Comparisons of two-, three-, and four-compartment models of body composition analysis in men and women. J Appl Physiol (1985) 85, 238-245.

8. Bunt JC, Lohman TG \& Boileau RA (1989) Impact of total body water fluctuations on estimation of body fat from body density. Med Sci Sports Exerc 21, 96-100.

9. Dixon CB, Ramos L, Fitzgerald E, et al. (2009) The effect of acute fluid consumption on measures of impedance and percent body fat estimated using segmental bioelectrical impedance analysis. Eur J Clin Nutr 63, 1115-1122.

10. Nana A, Slater GJ, Hopkins WG, et al. (2012) Effects of daily activities on DXA measurements of body composition in active people. Med Sci Sports Exerc 44, 180-189.

11. Thomsen TK, Jensen VJ \& Henriksen MG (1998) In vivo measurement of human body composition by dual-energy X-ray absorptiometry (DXA). Eur J Surg 164, 133-137.

12. Pietrobelli A, Wang Z, Formica C, et al. (1998) Dual-energy X-ray absorptiometry: fat estimation errors due to variation in soft tissue hydration. Am J Physiol 274, E808-E816.

13. Heiss CJ, Gara N, Novotny D, et al. (2009) Effect of a 1 litre fluid load on body composition measured by air displacement plethysmography and bioelectrical impedance. J Exerc Physiol Online 12, 1-8.

14. Gallagher M, Walker K \& O'Dea K (1998) The influence of a breakfast meal on the assessment of body composition using bioelectrical impedance. Eur J Clin Nutr 52, 94-97.

15. Rouillier MA, David-Riel S, Brazeau AS, et al. (2015) Effect of an acute high carbohydrate diet on body composition using DXA in young men. Ann Nutr Metab 66, 233-236.

16. Fields D, Higgins P \& Hunter G (2004) Assessment of body composition by air-displacement plethysmography: influence of body temperature and moisture. Dyn Med $\mathbf{3}, 3$.

17. Utter AC, Goss FL, Swan PD, et al. (2003) Evaluation of air displacement for assessing body composition of collegiate wrestlers. Med Sci Sports Exerc 35, 500-505.
18. Nana A, Slater GJ, Hopkins WG, et al. (2012) Techniques for undertaking dual-energy X-ray absorptiometry whole-body scans to estimate body composition in tall and/or broad subjects. Int J Sport Nutr Exerc Metab 22, 313-322.

19. Kerr A, Slater GJ, Byrne N, et al. (2016) Reliability of 2 different positioning protocols for dual-energy X-ray absorptiometry measurement of body composition in healthy adults. $J$ Clin Densitom 19, 282-289.

20. Ward LC, Isenring E, Dyer JM, et al. (2015) Resistivity coefficients for body composition analysis using bioimpedance spectroscopy: effects of body dominance and mixture theory algorithm. Physiol Meas 36, 1529.

21. Cornish BH, Ward LC, Thomas BJ, et al. (1996) Evaluation of multiple frequency bioelectrical impedance and Cole-Cole analysis for the assessment of body water volumes in healthy humans. Eur J Clin Nutr 50, 159-164.

22. Kyle UG, Bosaeus I, De Lorenzo AD, et al. (2004) Bioelectrical impedance analysis - part I: review of principles and methods. Clin Nutr 23, 1226-1243.

23. Dempster P \& Aitkens S (1995) A new air displacement method for the determination of human body composition. Med Sci Sports Exerc 27, 1692-1697.

24. Norton K, Whittingham N, Carter L, et al. (1996) Measurement techniques in anthropometry. In Anthropometrica, 1st ed., pp. 25-75 [K Norton, editor]. Kensington, NSW: University of New South Wales Press Ltd.

25. Evans EM, Rowe DA, Misic MM, et al. (2005) Skinfold prediction equation for athletes developed using a fourcomponent model. Med Sci Sports Exerc 37, 2006.

26. Nana A, Slater GJ, Hopkins WG, et al. (2012) Effects of daily activities on dual-energy X-ray absorptiometry measurements of body composition in active people. Med Sci Sports Exerc 44, 180-189.

27. Stewart AD \& Hannan J (2000) Sub-regional tissue morphometry in male athletes and controls using dual X-Ray absorptiometry (DXA). Int J Sport Nutr Exerc Metab 10, 157-169.

28. Hopkins WG, Marshall S, Batterham A, et al. (2009) Progressive statistics for studies in sports medicine and exercise science. Med Sci Sports Exerc 41, 3-12.

29. Norton K, Hayward S, Charles S, et al. (2000) The effects of hypohydration and hyperhydration on skinfold measurements. Kinanthropometry VI, Adelaide, 13-16 October 1998, pp. 253-266.

30. Oppliger RA \& Bartok C (2002) Hydration testing of athletes. Sports Med 32, 959-971.

31. Silva AM, Fields DA, Quitério AL, et al. (2009) Are skinfoldbased models accurate and suitable for assessing changes in body composition in highly trained athletes? J Strength Cond Res 23, 1688-1696.

32. De Lorenzo A, Andreoli A \& Candeloro N (1997) Withinsubject variability in body composition using dual-energy X-rayabsorptiometry. Clin Physiol 17, 383-388.

33. Hillier SE, Beck L, Petropoulou A, et al. (2014) A comparison of body composition measurement techniques. J Hum Nutr Diet 27, 626-631.

34. Anderson DE (2007) Reliability of air displacment plethysmography. J Strength Cond Res 21, 169-172.

35. Horber FF, Thomi F, Casez JP, et al. (1992) Impact of hydration status on body composition as measured by dual energy $\mathrm{X}$-ray absorptiometry in normal volunteers and patients on haemodialysis. Br J Radiol 65, 895-900.

36. Vilaça KHC, Ferriolli E, Lima NKC, et al. (2009) Effect of fluild and food intake on the body composition evaluation of elderley persons. J Nutr Health Aging 13, 183-186. 
37. Saunders MJ, Blevins JE \& Broeder CE (1998) Effects of hydration changes on bioelectrical impedance in endurance trained individuals. Med Sci Sports Exerc 30, 885-892.

38. Kyle UG, Bosaeus I, De Lorenzo AD, et al. (2004) Bioelectrical impedance analysis - part II: utilization in clinical practice. Clin Nutr 23, 1430-1453.

39. van Marken Lichtenbelt W, Westerterp KR \& Wouters L (1994) Deuterium dilution as a method for determining total body water: effect of test protocol and sampling time. Br J Nutr $\mathbf{7 2}$, 491-497.

40. Moon J, Tobkin S, Roberts M, et al. (2008) Total body water estimations in healthy men and women using bioimpedance spectroscopy: a deuterium oxide comparison. Nutr Metab (Lond) 5, 7.

41. Matias CN, Santos DA, Gonçalves EM, et al. (2013) Is bioelectrical impedance spectroscopy accurate in estimating total body water and its compartments in elite athletes? Ann Hum Biol 40, 152-156.
42. Maughan RJ, Shirreffs SM \& Leiper JB (2007) Errors in the estimation of hydration status from changes in body mass. J Sports Sci 25, 797-804.

43. Fuller N, Jebb S, Laskey M, et al. (1992) Four-component model for the assessment of body composition in humans: comparison with alternative methods, and evaluation of the density and hydration of fat-free mass. Clin Sci (Lond) 82, 687-693.

44. Cugini P, Salandri A, Petrangeli CM, et al. (1996) Circadian rhythms in human body composition. Chronobiol Int $\mathbf{1 3}$, 359-371.

45. Casa DJ, Clarkson PM \& Roberts WO (2005) American College of Sports Medicine roundtable on hydration and physical activity: consensus statements. Curr Sports Med Rep 4, 115-127.

46. Hamouti N, Coso JD, Ávila A, et al. (2010) Effects of athletes' muscle mass on urinary markers of hydration status. Eur J Appl Physiol 109, 213-219. 